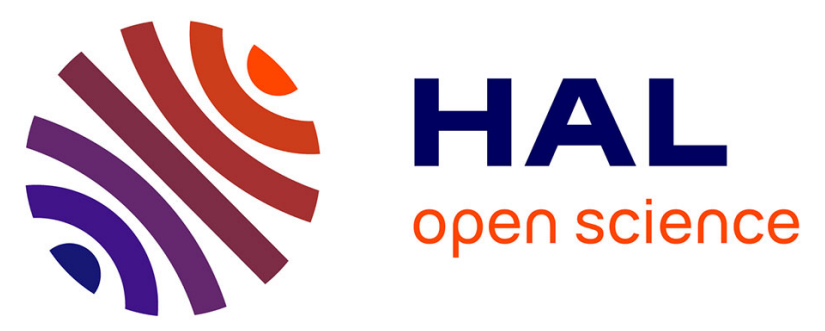

\title{
A robust enzyme-linked immunosorbent assay to measure serum ramucirumab concentrations
}

Celine Desvignes, David Ternant, Thierry Lecomte, Astrid Lièvre, Marc

Ohresser, Romain Chautard, William Raoul, Gilles Paintaud

\section{To cite this version:}

Celine Desvignes, David Ternant, Thierry Lecomte, Astrid Lièvre, Marc Ohresser, et al.. A robust enzyme-linked immunosorbent assay to measure serum ramucirumab concentrations. Bioanalysis, 2021, 13 (7), pp.565-574. 10.4155/bio-2020-0199 . inserm-03186974

\section{HAL Id: inserm-03186974 https://www.hal.inserm.fr/inserm-03186974}

Submitted on 1 Apr 2021

HAL is a multi-disciplinary open access archive for the deposit and dissemination of scientific research documents, whether they are published or not. The documents may come from teaching and research institutions in France or abroad, or from public or private research centers.
L'archive ouverte pluridisciplinaire $\mathbf{H A L}$, est destinée au dépôt et à la diffusion de documents scientifiques de niveau recherche, publiés ou non, émanant des établissements d'enseignement et de recherche français ou étrangers, des laboratoires publics ou privés. 
1 A robust enzyme-linked immunosorbent assay to measure serum ramucirumab concentrations 
Abstract:

Introduction: Ramucirumab, an anti-VEGFR2 monoclonal antibody, has been approved for the treatment of metastatic gastric and colorectal cancer. An assay measuring ramucirumab serum concentrations was needed to investigate its pharmacokinetics and concentrationresponse relationship.

Results: An ELISA was developed and validated according to the international guidelines for ligand binding assays. Ramucirumab calibration standards ranged from 0.125 to $40 \mathrm{mg} / \mathrm{L}$. Low, Middle and High Quality Controls were spiked at $0.2,4$ and $8 \mathrm{mg} / \mathrm{L}$, respectively. The limits of quantification were established to be 0.125 and $10 \mathrm{mg} / \mathrm{L}$ for LLOQ and ULOQ, respectively. No cross-reactivity with anti-VEGF or anti-EGFR was detected.

Conclusion: This in-house-developed ELISA is sensitive, accurate, reproducible, and suitable for pharmacokinetic studies of ramucirumab.

Keywords: Monoclonal antibody, ramucirumab, enzyme-linked immunosorbent assay, Pharmacokinetics, Therapeutic drug monitoring. 


\section{Introduction}

During the last two decades, the therapeutic arsenal against advanced malignancies was strengthened by the use of anti-angiogenic monoclonal antibodies (mAbs) or fusion proteins in addition to standard chemotherapy, as bevacizumab, aflibercept and later ramucirumab [14]. Ramucirumab was approved in gastric cancer $[5,6]$, aggressive non-small cell lung cancer [7], metastatic colorectal cancer [8] and hepatocellular carcinoma [9].

Ramucirumab, developed as IMC-1121B (ImClone Systems) and marketed as Cyramza ${ }^{\circledR}$ (LY3009806, Lilly), is a $147 \mathrm{kDa}$ fully human immunoglobulin G1 (IgG1א) mAb that targets extracellular domain of vascular endothelial growth factor receptor 2 (VEGFR-2). VEGFR-2 ligands include VEGF-A, formerly known as vascular permeability factor (VPF) and one of the most potent anti-angiogenic factors discovered and characterized in the $80 \mathrm{~s}[10,11]$. The intended target of ramucirumab is VEGFR-2 expressed on endothelial cells surface and its expected effect is an inhibition of the VEGF-A/VEGFR-2 axis involved in pathological angiogenesis. However, it is worth noting that the concept of direct effects of anti-angiogenic therapies on tumor cells themselves was only recently highlighted and reviewed by Simon et al. [12].

The administration of approved doses of ramucirumab leads to a large pharmacokinetic variability, which is influenced by several individual sources of variability as body weight [13]. In addition, other factors, as serum albumin levels or tumor burden may influence ramucirumab pharmacokinetics [14]. This variability is relevant, since ramucirumab concentrations lead to better clinical response. Indeed, higher ramucirumab exposure was 
associated with longer overall and progression-free survivals [15]. Thus, the interpretation of clinical efficacy of ramucirumab might benefit from accurately defined pharmacokinetic parameters $[16,17]$.

The present work focused on the development of an Enzyme Linked Immunosorbent Assay (ELISA) that measures accurately and reproductively ramucirumab concentrations for a large range of concentrations. A high level of sensitivity (i.e. very low LLOQ - Low Limit Of Quantification) is also required for future pharmacokinetic studies. This ELISA technique was developed under both European Medicines Agency (EMA) and US Food and Drug Administration (FDA) guidelines.

\section{Material and Methods}

Reagents

96-well plates were purchased from ThermoFisher Scientific (Nunc plates, Elancourt, France). Phosphate-buffered saline (PBS) was provided by Immuno Concepts (Sacramento, CA). Tween 20 was purchased from Biosolve (Dieuze, France), Bovine serum albumin (BSA), a polyvalent peroxidase-conjugated goat anti-IgG specific for Fc fragment (HRP-anti-human IgG; lot number 067M4885V and 127M4800V), and FAST o-phenylenediamine dihydrochloride tablets were purchased from Sigma-Aldrich (Saint-Quentin-Fallavier, France). A human recombinant protein of $82.5 \mathrm{kDa}$, soluble form of VEGFR-2 from Clinisciences (Nanterre, France), was used as the capture antigen. A stock solution of $10 \mathrm{mg} / \mathrm{ml}$ of ramucirumab (Cyramza ${ }^{\circledR}$ ) was purchased from Eli-Lilly (Indianapolis, IN, USA) through Reagent preparation 
The calibration standards and quality controls (QCs) prepared from a $10 \mathrm{mg} / \mathrm{ml}$ ramucirumab stock solution were aliquoted and stored at $+4^{\circ} \mathrm{C}$ until use or at $-20^{\circ} \mathrm{C}$ for long term. Concentrations of standard calibrators were the following $0.125,0.25,0.625,2.5,12.5,25$ and $40 \mathrm{mg} / \mathrm{l}$ and the concentrations of QCs were $0.2,4$ and $8 \mathrm{mg} / \mathrm{l}$. A 1:100 dilution in 1\% (w/v) PBS-BSA was prepared for all calibration standards, QCs and samples.

Assay procedure

Assay validation followed the procedure previously described [18-20]. Notably, coating was performed overnight at $+4^{\circ} \mathrm{C}$, by incubating $100 \mu \mathrm{L} /$ well of $2 \mathrm{mg} / \mathrm{l}$ sVEGFR-2 in carbonatebicarbonate buffer. Calibration standards, QCs and samples were incubated at $37^{\circ} \mathrm{C}$ during $1 \mathrm{~h}$ under agitation. One hundred microliters per well of HRP conjugated-anti IgG antibody (1:8000 dilution in 1\% PBS-BSA) was used. The final absorbance was read at 490 and $630 \mathrm{~nm}$ (for correction) on an ELx808 ELISA plate reader (BioTek, VT, USA). Non-specific background was determined with carbonate-bicarbonate buffer only. Serum ramucirumab concentrations were calculated with a 4-parameter logistic calibration curve $($ Response $=($ Min-Max $) /(1+$ (Concentration/Inflection point)^Slope + Max) implemented in Gen5 software (BioTek, VT, USA).

Precision, accuracy, limit of quantification

The precision and accuracy were assessed as previously described [18-20]. Briefly, intra- and inter-day precisions and accuracies were defined as coefficient of variation (\% CV $=$ Standard deviation (SD)/mean) and absolute bias (\% RE, where relative error $(\mathrm{RE})=[$ measured value actual value]/actual value), respectively. The limit of detection (LOD) was determined as 3 times the mean SD of the concentration of 11 blank samples. The LLOQ corresponded to the 
lowest calibration standard. The upper limit of quantification (ULOQ) was defined as the highest amount of ramucirumab that could be quantified with SD and RE $<20 \%$. The low $Q C$ value was within three times the LLOQ, the mid QC value was the geometric mean of the curve and the high QC was spiked at $80 \%$ of ULOQ.

\section{Matrix effect and other parameters}

To assess the matrix effect, we compared the precision and accuracy when QCs were prepared in PBS-BSA or normal human serum $(n=4)$ against calibrators prepared in PBS-BSA. The recovery percentage was calculated as (recovered concentration / spiked concentration) $\mathrm{x}$ 100. These results were compared using a non-parametric Mann-Whitney test. Dilution linearity, prozone, parallelism and stability were determined in agreement with our published methods without any particular modification [18-22].

\section{Selectivity \& specificity}

Selectivity was assessed using serum from healthy controls $(n=18)$ and serum from healthy controls spiked with rheumatoid factor $(55 \mathrm{UI} / \mathrm{ml}$ or $30 \mathrm{UI} / \mathrm{ml}$ or $15 \mathrm{UI} / \mathrm{ml}$ ) ( $\mathrm{n}=6$ for each). Analytical interference with other mAbs used in colorectal cancer patients was evaluated using serum samples from patients treated with anti-VEGF-A bevacizumab $(n=9)$, anti-EGFR (Epidermal Growth Factor Receptor) cetuximab ( $n=9)$ or VEGF-targeting fusion protein aflibercept $(n=9)$. Identical samples (except for aflibercept) were spiked with ramucirumab at a final concentration equal to $4 \mathrm{mg} / \mathrm{L}$. Normal human serum was spiked with aflibercept and ramucirumab at a ratio equal to $1: 1$ or $1: 5$. The impact of hemolyzed and lipemic samples spiked or not with ramucirumab $(=4 \mathrm{mg} / \mathrm{L})$ was also tested. In all cases, to consider there is no cross-reactivity, the concentrations of these samples had to be below the LLOQ of 
ramucirumab, ie $0.125 \mathrm{mg} / \mathrm{l}$.

Detection of unbound ramucirumab

Ramucirumab is a bivalent molecule and is able to bind two molecules of VEGFR2. When ramucirumab is binding to VEGFR2, it blocks activity and prevents fixation of VEGFA, VEGF-C and VEGF-D. During ramucirumab treatment, three different species may be present in the serum: free ramucirumab and ramucirumab bound to either 1 or 2 VEGFR2 molecules. Among these three species, biologically active species are free ramucirumab and ramucirumab monovalently bound to a molecule of VEGR2. Therefore, we tested our in-house ELISA by mixing serum samples containing ramucirumab (4 $\mathrm{mg} / \mathrm{L})$ with increasing ramucirumab:sVEGFR2 ratios of: 0:25, 1:0, 1:1, 1:5 and 1:25. We also tested ramucirumab (4 mg/L) mixed with increasing ramucirumab:VEGF-A ratios of: 0:100, 1:0, 1:1, 1:10 and 1:100. All mixes were incubated for 30 minutes at $37^{\circ} \mathrm{C}$. Each ratio was assayed on four occasions on the same day.

\section{Data interpretation: acceptance and rejection criterion}

Measurements were accepted if differences between duplicates were lower than $20 \%$ for more than $75 \%$ of the calibrators. Calibrators and QCs performances were validated when the intra- and inter-day precision and accuracy were between $\pm 20 \%$ ( $\pm 25 \%$ at LLOQ and ULOQ) and the total error $[|\mathrm{CVI}+| \mathrm{REI}]$ was between $\pm 30 \%$ ( $\pm 40 \%$ at the LLOQ and ULOQ). In order to be validated, the precision of each back-calculated concentration, had to be within $\pm 20 \%$ (dilution linearity) and $\pm 30 \%$ (parallelism) of the target concentration [23-29]. 
141 Concentrations were measured in serum samples collected from two patients treated for

142 advanced colorectal cancer by $8 \mathrm{mg} / \mathrm{kg}$ ramucirumab infusions every 2 weeks. These samples

143 are part of a declared biological collection $\left(\mathrm{N}^{\circ} \quad\right.$ ) and were in conformity with the

144 National Data Information and Freedom Commission (CNIL). Trough $(n=9)$ and peak $(n=9)$

145 samples were collected just before infusion and 2 hours after the end of the infusion, 146 respectively. This study was an ancillary study performed after the constitution of the declared 147 biological collection.

\section{Results}

Enzyme-Linked Immunosorbent assay

The chosen coating concentration led to reproducible standard calibration. A mean curve from

152 six individual calibration curves on 6 different days is given on Figure 1 . This latter was generated using ramucirumab concentrations from 0 to $40 \mathrm{mg} / \mathrm{l}$. The limits of quantification (LOD, LLOQ and ULOQ) (table 1) of the assay are within the range of our previously published ELISA methods [18-20].

Precision \& accuracy of the assay

Intra-day and inter-day reproducibility, precision and accuracy of calibration standards and QCs were within $-/+15 \%$ of the nominal value (Table 2 ). The total error was below $30 \%$ for all calibration standards.

Matrix effect and other parameters

Mean concentrations (CV, bias) of low $(0.2 \mathrm{mg} / \mathrm{l})$, medium $(4 \mathrm{mg} / \mathrm{l})$, and high $(8 \mathrm{mg} / \mathrm{l}) \mathrm{QCs}$ 
165

166

167

168

169

170

171

172

173

174

175

176

177

178

179

180

181

182

(4.77\%, 1.52\%), respectively. In human serum, mean concentration of QCs were $0.13 \mathrm{mg} / \mathrm{l}$ (7.93\%, -36.07\%), $3.23 \mathrm{mg} / \mathrm{l}(3.92 \%,-19.30 \%)$, and $6.36 \mathrm{mg} / \mathrm{l}(3.63 \%,-20.56 \%)$, respectively.

Concentrations of low QC prepared in human serum were significantly lower than those measured in PBS-BSA (Mann-Whitney test, $\mathrm{P}<0.05$ ). Therefore, the calibration standards and QCs were prepared in the same matrix as the samples as previously recommended by our team [19].

Dilution linearity \& prozone

A serum sample was spiked with ramucirumab at a concentration of $200 \mathrm{mg} / \mathrm{l}$ and was diluted $1: 10,1: 20,1: 50,1: 100,1: 500,1: 1000,1: 2000$ and $1: 5000$ in normal human serum $\pm 20 \%$, which is in accordance to EMA guideline (Figure 2) [26]. Therefore, samples can be diluted up to 1,000 -fold. No prozone effect was observed until a ramucirumab concentration of $1,000 \mathrm{mg} / \mathrm{l}$ (Figure 3). The dynamic range of the assay is therefore between $0.125-10 \mathrm{mg} / \mathrm{l}$, i.e. between the LLOQ and ULOQ of the assay.

\section{Parallelism}

Parallelism was assessed using different dilutions (1:25 to 1:1000) with a panel of three patient serum samples ( $n=1$ for each dilution). Patient's serum concentrations were respectively 192.56, 153.25 and $145.10 \mathrm{mg} / \mathrm{l}$. All measured concentrations were within the target concentration of $\pm 30 \%$ as recommended by guidelines on bioanalytical method validation [24, 26-28, 30], indicating that samples can be diluted up to 1,000-fold (Figure 4).

\section{Selectivity}

Selectivity of the assay was determined by using sera from healthy donors, from normal 
human serum spiked with rheumatoid factor and from patients treated with bevacizumab, cetuximab or aflibercept (Figure 5). All measured concentrations were below LLOQ. The same samples (except for aflibercept) were spiked with ramucirumab and all concentrations were equal to $4 \mathrm{mg} / \mathrm{L}( \pm 20 \%)$. For normal human serum spiked with aflibercept and ramucirumab at a ratio equal to $1: 1$ or $1: 5$, measured concentrations were also equal to $4 \mathrm{mg} / \mathrm{L}( \pm 20 \%)$.

The same results were obtained with hemolyzed and lipemic samples spiked or not with ramucirumab. These results revealed no analytical interference.

\section{Ramucirumab concentrations after addition of sVEGFR2 or VEGF-A}

Mean ramucirumab concentrations (SD) were $0.1(0.01), 3.6(0.28), 1.7(0.19), 0.3(0.01)$ and

$0.2(0.00) \mathrm{mg} / \mathrm{L}$ for $0: 25$ (negative control), 1:0 (positive control), 1:1, 1:5 and 1:25 ramucirumab to sVEGFR2 respectively.

Mean ramucirumab concentrations (SD) were <LLOQ (not calculated), 4.1 (0.27), $4.3(0.24)$, $3.4(0.33)$ and $2.0(0.14) \mathrm{mg} / \mathrm{L}$ for $0: 100$ (negative control), 1:0 (positive control), 1:1, 1:10 and 1:100 ramucirumab to VEGF-A respectively.

\section{Stability}

The three concentration levels maintained at room temperature, $+4^{\circ} \mathrm{C}$ and $-20^{\circ} \mathrm{C}$ were all stable up to 14 days, 28 days and 180 days, respectively (Supplemental figure 1). Samples were stable up to 7 freeze-thaw cycles (Supplemental figure 2). In all cases, the relative error was below $20 \%$.

\section{Patients samples concentrations}

Ramucirumab serum concentrations were measured in 2 patients treated for metastatic 
colorectal cancer and were both above LLOQ except for baseline concentration $(0 \mathrm{mg} / \mathrm{l})$. Median (range) trough and peak concentrations during treatment were respectively 26.6 (9.356.9) $\mathrm{mg} / \mathrm{l}$ and $156.0(93.3-243.0) \mathrm{mg} / \mathrm{l}$.

\section{Discussion}

To our knowledge, this is not the first ELISA technique that was published to measure ramucirumab concentrations. Three other techniques have been published so far, but present considerable differences with our technique, including limits of quantification. The advantage of our in-house ELISA is characterized by a lower LLOQ $(0.125 \mathrm{mg} / \mathrm{l}$ vs $0.5 \mathrm{mg} / \mathrm{l}$ [31] and $2.5 \mathrm{mg} / \mathrm{l}[32])$ and a higher ULOQ (10 mg/l vs $0.2 \mathrm{mg} / \mathrm{l})$ [33]. Furthermore, we report here more detailed information about intra- and inter-run variabilities, selectivity, interferences, and dilution-induced inaccuracy or imprecision on our development and validation method.

This high sensitivity of our assay allowed measuring very low concentrations. To our knowledge, the pharmacokinetics of ramucirumab was investigated in only one study using population PK modelling. We therefore believe that this pharmacokinetic, notably the elimination decay still has to be thoroughly investigated. This can only be done using an assay able to measure low concentrations that are observed after single doses or when treatment is discontinued. These measurements are needed for an accurate estimation of pharmacokinetic parameters. A sensible assay is even more mandatory if a nonlinear targetmediated elimination has to be studied. This level of sensitivity may not be useful for clinical trials, but is mandatory for pharmacokinetic studies a feature needed to estimate pharmacokinetic parameters in future studies.

An exposure-response relationship has been observed from randomized trials of ramucirumab 
in lung cancer, gastric cancer and colorectal cancer [15, 34, 35]. Therefore, a fully validated

assay is required to thoroughly investigate ramucirumab pharmacokinetics (doseconcentration relationship) and concentration-effect relationship, either in clinical trials or in routine clinical use of this drug. Moreover, the understanding of the interindividual variability of ramucirumab clinical response has to be made with respect to a sound assessment of its concentration-effect relationship, in order to determine the optimal dosing regimen which maximizes patients survival, while minimizing the risk of adverse events [36, 37].

In the context of daily clinical practice with samples from our registered biological collection, concentrations ranged from $26.6 \mathrm{mg} / \mathrm{l}$ to $156 \mathrm{mg} / \mathrm{l}$ ), corresponding to through and peak concentrations, respectively. This range of quantification is in accordance with the values reported in clinical studies, i.e. 49.5 [6.3-228 mg/l] to $74.4 \mathrm{mg} / \mathrm{l}[13.8-234 \mathrm{mg} / \mathrm{l}])$ [38] or 49.7 to $81.1 \mathrm{mg} / \mathrm{L}$ for Cohn et al. [34] which confirms the relevance of measurements provided by our ELISA technique.

\section{To eliminate matrix effect for low QC concentration in human serum, the calibration standards} and QCS were prepared in human pooled serum. In the present study, we observed no analytical interference with bevacizumab, cetuximab or aflibercept. This result reveals that our ELISA may be also useful to measure serum ramucirumab concentration in patients concomitantly or previously treated with an anti-VEGF or an anti-EGFR biopharmaceutical. Moreover, since our ELISA is based on the capture of ramucirumab by SVEGFR2, i.e. ramucirumab unbound or bound to one sVEGFR2. In order to confirm this hypothesis, we tested ramucirumab mixed with increasing concentrations of sVEGFR2. Measured ramucirumab concentration decreased when the amount of SVEGFR2 increased. When 
ramucirumab and sVEGFR2 were equimolar, measured ramucirumab concentration

262

263

264

265

decreased to nearly $50 \%$ of that obtained in the absence of SVEGFR2. Our test may reflect unbound ramucirumab, since almost total signal inhibition occurs for molecular ratio above 1:5. The influence of VEGFA was also tested by measuring concentrations in normal human serum spiked with ramucirumab with or without VEGFA. The ramucirumab concentration is not affected by for equimolar ratio and decreased by half for ratio 1:100. The difference between the two targets is explained by a higher affinity of ramucirumab for VEGR2. These two experiments revealed that our concentration measurement reflects the unbound fraction of ramucirumab.

\section{Conclusion}

Overall, we developed and validated an immunoassay that is suitable for measuring serum concentrations of ramucirumab in treated patients according to guideline criteria. Our assay is sensitive, reproducible and accurate and thus can be used in both pharmacokinetic studies and future therapeutic drug monitoring of ramucirumab.

\section{Future perspective}
In the

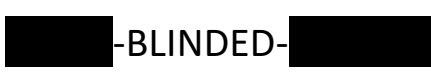
clinical
trial

the measure of ramucirumab concentrations, will allow better understanding of the relationship between ramucirumab concentrations and clinical outcomes in advanced gastric cancer in elderly patients, which has never been evaluated before. 


\section{Ethical conduct of research}

286 The authors state that they have obtained appropriate institutional review board approval or

287 have followed the principles outlined in the Declaration of Helsinki for all human or animal 288 experimental investigations. In addition, for investigations involving human subjects, 289 informed consent has been obtained from the participants involved. 
Background

- Pharmacokinetic and concentration-response studies of ramucirumab, a full human anti-VEGFR-2 monoclonal antibody, require a validated and robust analytical method.

Experimental section

- An ELISA using sVEGFR-2 coated microtiter plates was developed.

- The assay was validated according to International guidelines (EMA \& FDA).

Results

- The assay enables the reproducible measurement of ramucirumab concentrations in human serum.

- The range of quantification is 0.125 to $10 \mathrm{mg} / \mathrm{l}$.

Conclusion

- The assay is sensitive and accurate, and suitable for both pharmacokinetic studies and, potentially, therapeutic drug monitoring of ramucirumab. 
294 Papers of special note have been highlighted as: • of interest; $\bullet \bullet$ of considerable interest;

1. Arnold D, Fuchs CS, Tabernero J et al. Meta-analysis of individual patient safety data from six randomized, placebo-controlled trials with the antiangiogenic VEGFR2-binding monoclonal antibody ramucirumab. Annals of oncology : official journal of the European Society for Medical Oncology 28(12), 2932-2942 (2017).

2. Hurwitz H, Fehrenbacher L, Novotny $W$ et al. Bevacizumab plus irinotecan, fluorouracil, and leucovorin for metastatic colorectal cancer. The New England journal of medicine 350(23), 2335-2342 (2004).

3. Ibrahim S, Girault A, Ohresser M et al. Monoclonal Antibodies Targeting the IL-17/IL-17RA Axis:

4. Van Cutsem E, Tabernero J, Lakomy R et al. Addition of aflibercept to fluorouracil, leucovorin,

5. Fuchs CS, Tomasek J, Yong CJ et al. Ramucirumab monotherapy for previously treated

6. Wilke H, Muro K, Van Cutsem E et al. Ramucirumab plus paclitaxel versus placebo plus paclitaxel in patients with previously treated advanced gastric or gastro-oesophageal junction adenocarcinoma (RAINBOW): a double-blind, randomised phase 3 trial. The Lancet. Oncology 15(11), 1224-1235 (2014).

Garon EB, Ciuleanu TE, Arrieta O et al. Ramucirumab plus docetaxel versus placebo plus docetaxel for second-line treatment of stage IV non-small-cell lung cancer after disease progression on platinum-based therapy (REVEL): a multicentre, double-blind, randomised phase 3 trial. Lancet 384(9944), 665-673 (2014).

8. Yoshino $\mathrm{T}$, Portnoy DC, Obermannova R et al. Biomarker analysis beyond angiogenesis: RAS/RAF mutation status, tumour sidedness, and second-line ramucirumab efficacy in patients with metastatic colorectal carcinoma from RAISE-a global phase III study. Annals of oncology : official journal of the European Society for Medical Oncology 30(1), 124-131 (2019). hepatocellular carcinoma and increased alpha-fetoprotein concentrations (REACH-2): a 
randomised, double-blind, placebo-controlled, phase 3 trial. The Lancet. Oncology 20(2), 282296 (2019).

10. Ferrara N. Vascular endothelial growth factor. Arteriosclerosis, thrombosis, and vascular biology 29(6), 789-791 (2009).

11. Leung DW, Cachianes G, Kuang WJ, Goeddel DV, Ferrara N. Vascular endothelial growth factor is a secreted angiogenic mitogen. Science 246(4935), 1306-1309 (1989).

12. Simon T, Gagliano T, Giamas G. Direct Effects of Anti-Angiogenic Therapies on Tumor Cells:

13. O'brien L, Westwood P, Gao L, Heathman M. Population pharmacokinetic meta-analysis of ramucirumab in cancer patients. British journal of clinical pharmacology 83(12), 2741-2751 (2017).

14. Bensalem A, Ternant D. Pharmacokinetic Variability of Therapeutic Antibodies in Humans: A Comprehensive Review of Population Pharmacokinetic Modeling Publications. Clinical pharmacokinetics 59(7), 857-874 (2020).

15. Tabernero J, Ohtsu A, Muro K et al. Exposure-Response Analyses of Ramucirumab from Two

16. Passot C, Pouw MF, Mulleman D et al. Therapeutic Drug Monitoring of Biopharmaceuticals

17. Ternant $\mathrm{D}$, Paintaud G. Pharmacokinetics and concentration-effect relationships of therapeutic

18. Desvignes C, Edupuganti SR, Darrouzain F et al. Development and validation of an enzyme-

19. Desvignes C, Passot C, Ternant D et al. Development and validation of an ELISA to study

20. Passot C, Desvignes C, Ternant D et al. Development and validation of an enzyme-linked

21. Ceze N, Ternant D, Piller F et al. An enzyme-linked immunosorbent assay for therapeutic drug monitoring of cetuximab. Therapeutic drug monitoring 31(5), 597-601 (2009). 

bevacizumab pharmacokinetics. Therapeutic drug monitoring 32(5), 647-652 (2010).

•• An enzyme-linked immunosorbent assay for the therapeutic drug monitoring of bevacizumab.

23. Desilva B, Smith $\mathrm{W}$, Weiner $\mathrm{R}$ et al. Recommendations for the bioanalytical method validation of ligand-binding assays to support pharmacokinetic assessments of macromolecules. Pharmaceutical research 20(11), 1885-1900 (2003).

24. Kaza M, Karazniewicz-Lada M, Kosicka K, Siemiatkowska A, Rudzki PJ. Bioanalytical method validation: new FDA guidance vs. EMA guideline. Better or worse? Journal of pharmaceutical and biomedical analysis 165 381-385 (2019).

25. Smolec J, Desilva B, Smith $\mathrm{W}$ et al. Bioanalytical method validation for macromolecules in support of pharmacokinetic studies. Pharmaceutical research 22(9), 1425-1431 (2005).

26. EMA. Guideline on bioanalytical method validation. (2011).

-• Bioanalytical method validation from European Agency guidelines.

27. FDA. Guidance for Industry. Bioanalytical Method Validation. (2013).

28. FDA. Guidance for Industry. Bioanalytical Method Validation. (2018).

29. Islam R, Briscoe C, Bower J et al. 11th GCC Closed Forum: cumulative stability; matrix stability;

30. O'hara DM, Theobald V, Egan AC et al. Ligand binding assays in the 21st century laboratory:

31. Chiorean EG, Hurwitz HI, Cohen RB et al. Phase I study of every 2- or 3-week dosing of

32. Moore M, Gill S, Asmis T et al. Randomized phase II study of modified FOLFOX-6 in combination ramucirumab, a human immunoglobulin G1 monoclonal antibody targeting the vascular endothelial growth factor receptor-2 in patients with advanced solid tumors. Annals of oncology : official journal of the European Society for Medical Oncology 26(6), 1230-1237 (2015).

with ramucirumab or icrucumab as second-line therapy in patients with metastatic colorectal cancer after disease progression on first-line irinotecan-based therapy. Annals of oncology : official journal of the European Society for Medical Oncology 27(12), 2216-2224 (2016). 
33. Spratlin JL, Cohen RB, Eadens $\mathrm{M}$ et al. Phase I pharmacologic and biologic study of ramucirumab (IMC-1121B), a fully human immunoglobulin G1 monoclonal antibody targeting the vascular endothelial growth factor receptor-2. Journal of clinical oncology : official journal of the American Society of Clinical Oncology 28(5), 780-787 (2010).

34. Cohn AL, Yoshino T, Heinemann V et al. Exposure-response relationship of ramucirumab in patients with advanced second-line colorectal cancer: exploratory analysis of the RAISE trial. Cancer chemotherapy and pharmacology 80(3), 599-608 (2017).

\section{- Pharmacokinetic and pharmacodynamic evaluation of ramucirumab.}

35. Smit EF, Garon EB, Reck M et al. Exposure-response relationship for ramucirumab from the randomized, double-blind, phase 3 REVEL trial (docetaxel versus docetaxel plus ramucirumab) in second-line treatment of metastatic non-small cell lung cancer. Cancer chemotherapy and pharmacology 82(1), 77-86 (2018).

- Pharmacokinetic and pharmacodynamic evaluation of ramucirumab.

36. Ibrahim S, Raoul W, Lecomte T, Paintaud G, Ternant D. Pharmacokinetics partly explains the relationship between carcinoembryonic antigen level and survival of colorectal cancer patients treated with ramucirumab. European journal of cancer 92 119-120 (2018).

37. Yoshino T, Obermannova R, Bodoky $\mathrm{G}$ et al. Baseline carcinoembryonic antigen as a predictive factor of ramucirumab efficacy in RAISE, a second-line metastatic colorectal carcinoma phase III trial. European journal of cancer 78 61-69 (2017).

38. EMA. Cyramza European public assessment report. (2015). 
417

418

419

420

421

422

Table 1. Limits of detection and quantification of the assay.

\begin{tabular}{cc}
\hline Parameter & Value $(\mathrm{mg} / \mathrm{l})$ \\
\hline LOD & 0.02 \\
LLOQ & 0.125 \\
ULOQ & 10.00 \\
\hline
\end{tabular}

Table 2. Intra and interday precision, accuracy and total error of calibration standards and

quality controls.

\begin{tabular}{|c|c|c|c|c|c|c|c|c|}
\hline \multirow{2}{*}{$\begin{array}{c}\text { Spiked } \\
\text { concentration }\end{array}$} & \multicolumn{2}{|c|}{$\begin{array}{c}\text { Measured } \\
\text { concentration } \\
(\mathrm{mg} / \mathrm{l})\end{array}$} & \multicolumn{2}{|c|}{$\begin{array}{l}\text { Precision } \\
\text { (CV\%) }\end{array}$} & \multicolumn{2}{|c|}{$\begin{array}{c}\text { Accuracy } \\
\text { (\%RE) }\end{array}$} & \multicolumn{2}{|c|}{$\begin{array}{c}\text { Total error } \\
\text { (\%CV + \%RE) }\end{array}$} \\
\hline & $\begin{array}{c}\text { Intraday } \\
(n=9)\end{array}$ & $\begin{array}{c}\text { Interday } \\
(n=12)\end{array}$ & $\begin{array}{c}\text { Intraday } \\
(n=9)\end{array}$ & $\begin{array}{c}\text { Interday } \\
(n=12)\end{array}$ & $\begin{array}{c}\text { Intraday } \\
(n=9)\end{array}$ & $\begin{array}{c}\text { Interday } \\
(n=12)\end{array}$ & $\begin{array}{c}\text { Intraday } \\
(n=9)\end{array}$ & $\begin{array}{c}\text { Interday } \\
(n=12)\end{array}$ \\
\hline \multicolumn{9}{|l|}{$\begin{array}{l}\text { Calibration } \\
\text { standards } \\
(\mathrm{mg} / \mathrm{l})\end{array}$} \\
\hline 40 & 40.50 & 42.59 & 6.97 & 13.60 & 1.25 & 6.49 & 8.22 & 20.08 \\
\hline 25 & 24.04 & 26.65 & 7.18 & 7.88 & 3.83 & 2.60 & 11.01 & 10.48 \\
\hline 12.5 & 12.96 & 12.42 & 2.67 & 3.25 & 3.67 & 0.61 & 6.35 & 3.87 \\
\hline 2.5 & 2.45 & 2.51 & 1.13 & 2.26 & 1.86 & 0.45 & 3.00 & 2.71 \\
\hline 0.625 & 0.67 & 0.65 & 2.21 & 5.04 & 7.71 & 4.03 & 9.93 & 9.07 \\
\hline 0.25 & 0.22 & 0.22 & 3.35 & 5.67 & 10.46 & 13.06 & 13.81 & 18.73 \\
\hline 0.125 & 0.11 & 0.12 & 6.34 & 10.44 & 10.37 & 5.90 & 16.72 & 16.34 \\
\hline \multicolumn{9}{|l|}{$\mathrm{QCs}(\mathrm{mg} / \mathrm{l})$} \\
\hline $8(n=12)$ & 7.58 & 7.80 & 7.92 & 8.96 & 5.29 & 2.49 & 13.21 & 11.45 \\
\hline $4(n=12)$ & 3.53 & 3.75 & 6.02 & 8.31 & 11.79 & 6.35 & 17.81 & 14.66 \\
\hline $0.2(n=12)$ & 0.20 & 0.22 & 3.48 & 5.57 & 1.40 & 10.63 & 4.87 & 18.20 \\
\hline
\end{tabular}




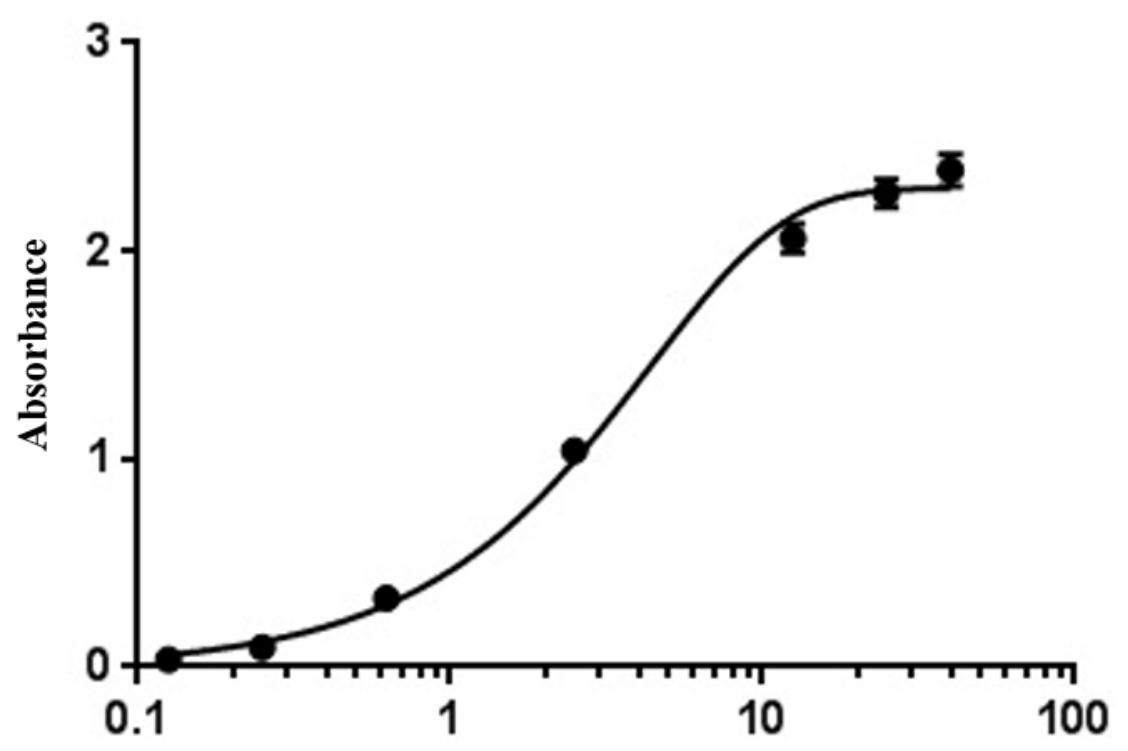

Ramucirumab Log-transformed concentrations

Figure 1. Mean standard curve of ramucirumab ELISA.

428 Six curves were obtained on 6 different days. Eight calibration standards were prepared in

429 normal human serum in a wide range of concentrations ( 0 to $40 \mathrm{mg} / \mathrm{l}$ ). Results were used to 430 assess the four-parametric logistic standard curve. The error bars represent standard 431 deviations.

432

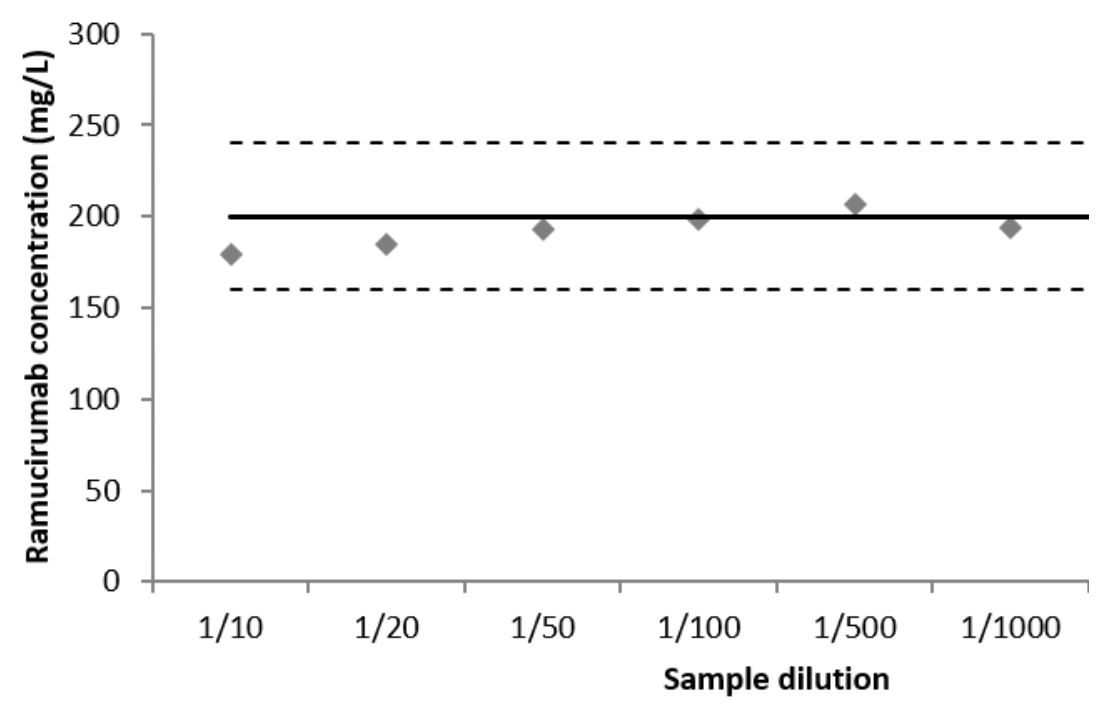


437 are displayed as dashed lines.

438

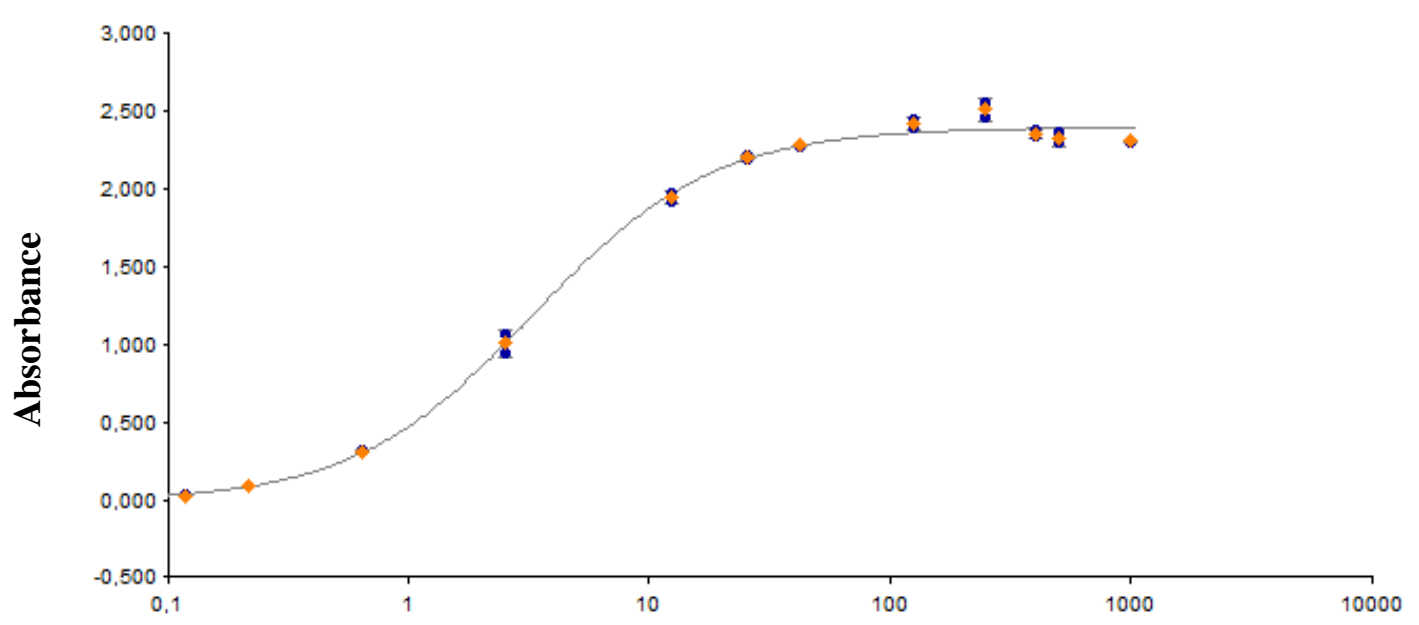

439

Ramucirumab Log-transformed

440

441 Figure 3. Research of a prozone with ramucirumab ELISA. A four parametric curve was

442 produced using ramucirumab concentrations up to $1,000 \mathrm{mg} / \mathrm{l}$.

443

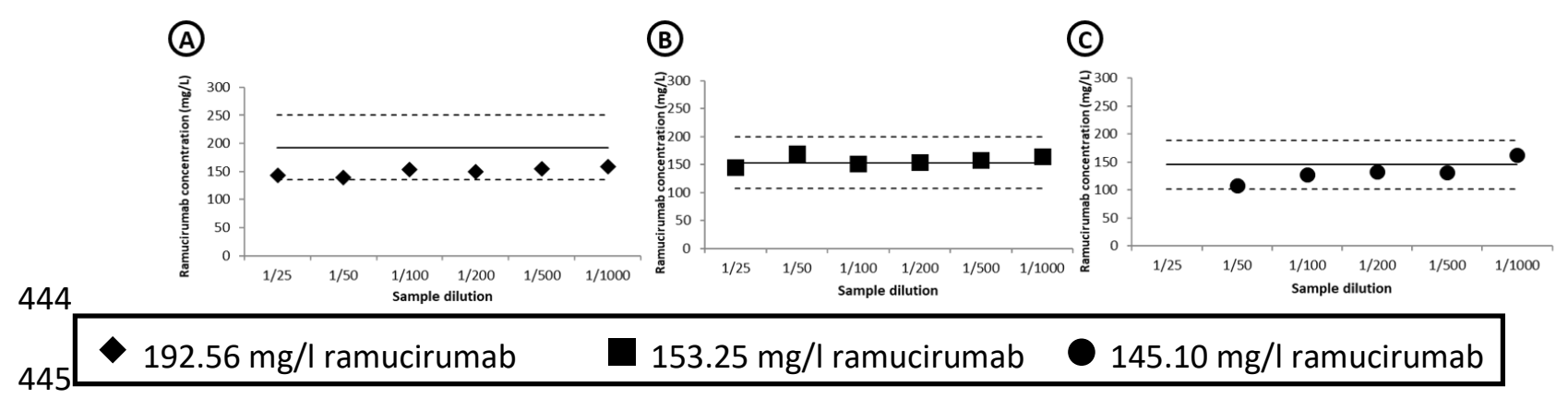

446

447 Figure 4. Parallelism of ramucirumab ELISA. Three different patient sera samples containing

$448192.56 \mathrm{mg} / \mathrm{I}$ (A), $153.25 \mathrm{mg} / \mathrm{l}$ (B) or $145.10 \mathrm{mg} / \mathrm{l}$ (C) were diluted up to 1,000 fold. Target

449 concentration is represented as solid line and $\pm 30 \%$ are figured with dashed lines. 


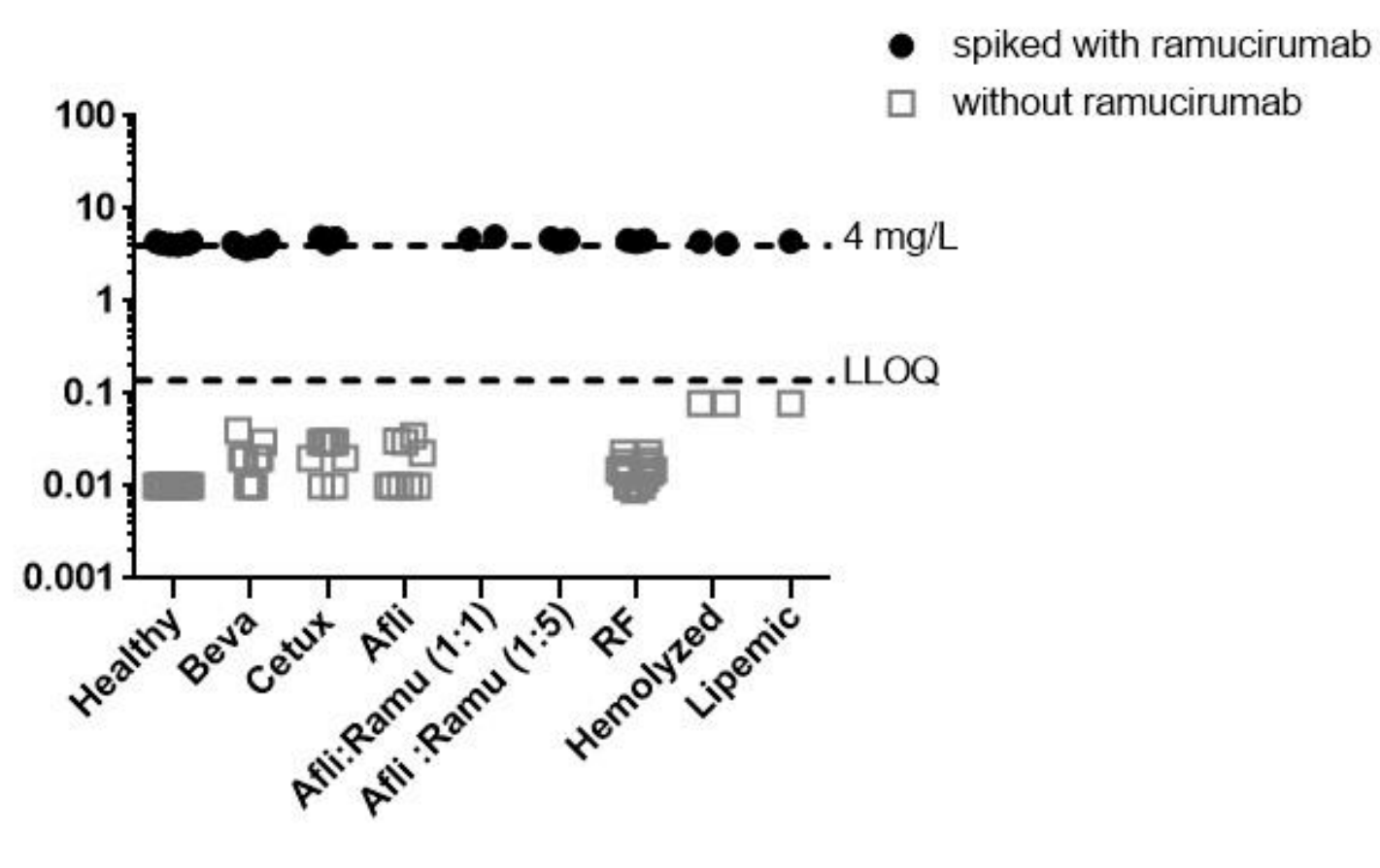

450

451 Figure 5. Assay selectivity. Selectivity was tested with sera from healthy donors, sera from

452 patients treated with bevacizumab, cetuximab, normal human serum spiked with aflibercept 453 or rheumatoid factor (RF). Ramucirumab concentration was measured in all samples spiked 454 or not with ramucirumab. The same tests were done in hemolyzed and lipemic samples. 455 (LLOQ: Lower limit of quantification).

456
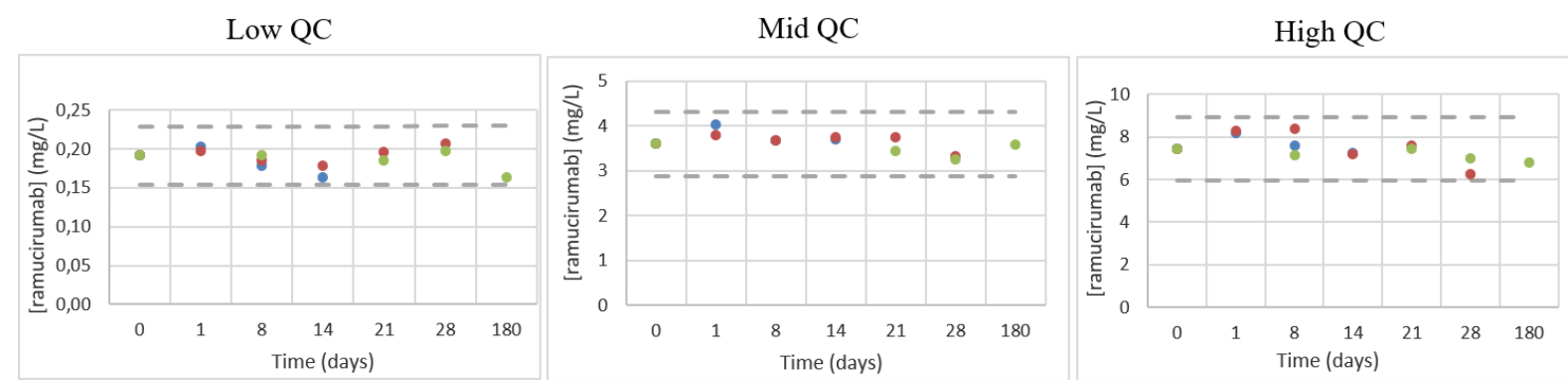

457

$$
\text { - } \mathrm{RT} \quad+44^{\circ} \mathrm{C} \quad-20^{\circ} \mathrm{C}
$$

Supplemental figure 1. Stability of the samples according to storage temperature. Quality controls were stored at different conditions for various durations. Ramucirumab 

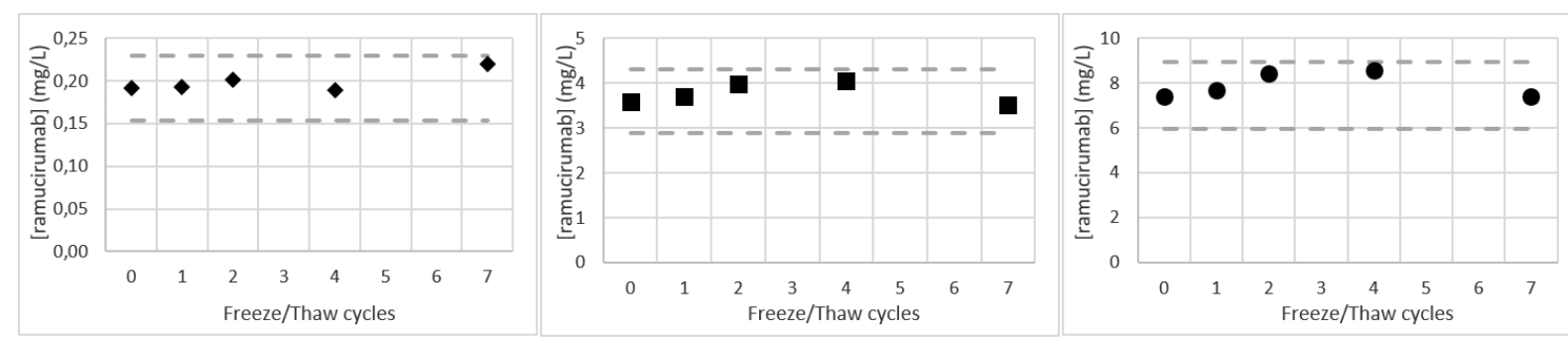

464 Supplemental figure 2. Stability of the samples according to the number of freeze/thaw

465 cycles. Samples were frozen at $-20^{\circ} \mathrm{C}$ and thawed at room temperature. The freeze/thaw cycle

466 was repeated up to 7 times and ramucirumab concentrations was then measured. Dashed 467 lines represent $\pm 20 \%$ of the concentration of the corresponding QC. 